\title{
Model of Flexibility in the Conceptual Evolution of Multiplicative Comparison
}

\author{
Graça Cebola@a \\ Joana Brocardo b \\ ${ }^{a}$ Instituto Politécnico de Portalegre, Escola Superior de Educação e Ciências Sociais, Portalegre, Portugal \\ ${ }^{\mathrm{b}}$ Instituto Politécnico de Setúbal, Escola Superior de Educação, Setúbal, Portugal
}

Received for publication on 28 Oct 2020. Accepted after review on 6 Sep. 2021. Designated editor: Claudia Lisete Oliveira Groenwald

\begin{abstract}
Background: Proportionality is a paramount topic in students' mathematical literacy. In this topic, it is fundamental to understand the multiplicative comparison and the flexible use of the concepts of ratio and proportion. Objectives: To analyse the articulation between concepts, resolution strategies, and representations used by students, supported by numerical relationships and properties of operations to characterise a model of the conceptual evolution of multiplicative comparison. Design: Research based design. Setting and participants: Two mathematics teachers teaching 6 th grade (11-12-year-old students) and their $38(18+20)$ students during the lessons in which five assignments were explored. Data collection and analysis: The data includes the transcription of the video recordings of the classes and the students' written productions. The data were successively revisited and condensed to identify and illustrate the aspects that make up the model of the conceptual evolution of multiplicative comparison. Results: The construction of the concept of multiplicative comparison prevails in the work in two spaces of measurement and in the exploration of the multiplicative relationship between the corresponding quantities within each one. Resolution strategies are first non-quantitative and become quantitative, initially with additive and then multiplicative characteristics. The representations are based on the ratio as a fraction, on the double number line, and on the table of ratios, being supported by numerical relationships and properties of operations. Conclusions: The results elucidate, adjust, and illustrate a theoretical model related to the evolution of the multiplicative comparison in two spaces of measurement.
\end{abstract} tions.

Keywords: Multiplicative comparison; Flexibility; Strategies; Representa-

Corresponding author: Graça Maria Cebola. Email: gracacebola@ipportalegre.pt 


\section{Modelo de flexibilidade na evolução conceptual da comparação multiplicativa}

\section{RESUMO}

Contexto: A proporcionalidade é um tópico de reconhecida importância ao nível da literacia matemática dos alunos. Neste tópico é fundamental a compreensão da comparação multiplicativa e do uso flexível dos conceitos de razão e proporção. Objetivos: Analisar a articulação entre conceitos, estratégias de resolução e representações utilizadas pelos alunos, suportadas por relações numéricas e propriedades das operações a fim de caracterizar um modelo da evolução conceptual da comparação multiplicativa. Design: Research based design. Ambiente e participantes: Duas professoras de Matemática a lecionar o $6 .^{\circ}$ ano (alunos maioritariamente com 12 anos) e os seus 38 $(18+20)$ alunos durante as aulas em que foram exploradas cinco tarefas. Coleta e análise de dados: Os dados incluem a transcrição dos registos vídeo das aulas e as produções escritas dos alunos. Os dados foram sucessivamente revisitados e condensados de modo a identificar e ilustrar os aspetos que integram o modelo de evolução conceptual da comparação multiplicativa. Resultados: A construção do conceito de comparação multiplicativa prevalece no trabalho em dois espaços de medida e na exploração da relação multiplicativa entre as quantidades correspondentes dentro de cada um. As estratégias de resolução começam por ser não quantitativas e transformamse em quantitativas com características inicialmente aditivas e depois multiplicativas. As representações baseiam-se na razão sob a forma de fração, na linha numérica dupla e na tabela de razões, sendo sustentadas em relações numéricas e propriedades das operações. Conclusões: Os resultados elucidam, ajustam e ilustram um modelo teórico relativo à evolução da comparação multiplicativa em dois espaços de medida. sentações.

Palavras-chave: comparação multiplicativa; flexibilidade; estratégias; repre-

\section{INTRODUCTION}

Proportionality is a topic that integrates the mathematics curricula of the various countries that, together with the importance of the concepts of ratio and proportion that are associated with it, highlight their importance in the interpretation and resolution of citizens' everyday life problems.

From the point of view of mathematics learning progression, several authors emphasise the importance of proportionality, considering that it combines the consolidation of the mathematical knowledge already acquired with the construction of foundations for higher school mathematics and algebraic reasoning (Langrall \& Swafford, 2000). In fact, limited knowledge of the multiplication and division operations and the rational numbers represented in decimal or fraction form negatively influences the understanding of the notions of ratio and proportion (Pittalis, Christou, \& Papageorgiou, 2003). Working on proportionality involves consolidating the knowledge of operations with positive rational numbers, their properties, and relationships, combining it with 
what Lamon (2007) refers to as a more consolidated and sophisticated view of multiplicative reasoning and the comparison of quantities in relative terms, aspects in which this article focuses.

To promote meaningful learning in mathematics, it is important to intertwine the relevant mathematical content with the development of mathematical skills related, for example, to mathematical reasoning and problem-solving. As the NRC (2001) emphasises, meaningful learning is related to mathematical proficiency, a construct that integrates conceptual understanding (understanding of mathematical concepts, operations, and relationships), the fluency of procedures (competence to perform procedures flexibly, accurately, efficiently, and appropriately), strategic competence (ability to formulate, represent and solve mathematical problems), adaptive reasoning (capacity for logical thinking, reflection, explanation, and justification) and what they call productive tendency, i.e., the common tendency to see mathematics as sensible, useful, and interesting and also to believe in its zeal and its own effectiveness.

All these elements of mathematical proficiency have been widely discussed at the level of mathematics education. However, studies on flexibility in mathematics have focused mainly on the flexibility in mental calculation (Threlfall, 2009; Rathgeb-Schnierer \& Green, 2013).

In this article, we deepen the concept of flexibility that the NCTM (2014) articulates with that of fluency in mathematics, which they consider to be closely related to the flexible choice of methods and strategies for solving problems in a context that may or may not be mathematical, and we go further, as we combine the study of multiplicative comparison with that of flexibility, aspects little studied in the literature in a joint manner. We focus on the concepts of multiplicative factor, ratio, and proportion and the connections between the understanding of concepts, the resolution strategies, and the representations used, supported by numerical relationships and the properties of operations, aiming at a model that characterises flexibility in multiplicative comparison. Specifically, its objective is to support and illustrate a model that translates flexibility into the conceptual evolution of multiplicative comparison.

\section{CONCEPTUAL EVOLUTION OF MULTIPLICATIVE COMPARISON}

A situation of proportionality is based on the multiplicative relationships existing between the quantities that compose it. Vergnaud $(1983,1988)$ uses a model based on the concept of space of measurement that allows giving meaning to the approach of situations of this kind. He defines measurement 
space in terms of physical magnitudes such as length, mass, money or even people. All these magnitudes can be quantified and, as such, the values corresponding to them are designated by quantities. A proportion is, therefore, a multiplicative relationship between the quantities of two spaces of measurement that Vergnaud $(1983,1988)$ schematises as shown in figure 1.

\section{Figure 1}

Vergnaud's conceptual scheme for proportions.

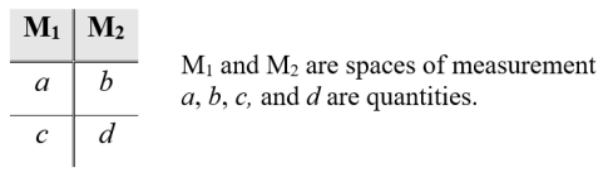

In a proportional situation, the quantities between spaces of measurement and within each one are always related in a multiplicative way. For example, between the two spaces of measurement $\mathrm{M}_{1}$ e $\mathrm{M}_{2}$ we have $b=k \times a$ and $\mathrm{d}=k \times c$, where $k$ is a constant (proportionality constant, functional factor). The generalisation of this situation allows us to consider its algebraic translation as a linear equation of the type $y=k x(k \neq 0)$, whose graphical representation is illustrated by a positive slope line that passes through the origin.

The scheme in figure 1 also allows us to show that, within the same measurement space, the relationship between quantities is still multiplicative. This characteristic allows us, when interpreting the relationship as a fraction, to consider multiple equivalent fractions. With this exploration, we transform the Vergnaud scheme into a table with more lines in which the respective values arise, first through the multiple integers and, later (and depending on the context in question), through any real factor (scalar factor).

Still in situations of multiplicative comparison with two spaces of measurement, Cramer, Post, and Currier (1993) refer that in problems of omitted value, in which three of the four values of a proportion are indicated and whose objective is to determine the missing value (or omitted term), the multiplicative relationships with non-integer factors, between and within the two spaces of measurement, present a greater degree of difficulty because the students do not understand the procedures that lead them to properties in other numerical fields.

However, when we refer to the type of problems used in the investigation that allows us to evaluate the ability to reason proportionally and discuss the concepts of ratio and proportion, problems of comparison between two ra- 
tios also emerge (Cramer, Post, \& Currier, 1993; Lamon, 2007). Known examples of this type of problems are those that seek to compare the taste of orange juices when different numbers of cups of concentrate and water are indicated.

A ratio is defined as a comparative relationship between two quantities or two spaces of measurement (NRC, 2001) or as the result of comparing multiplicatively two quantities (Thompson, 1994). Freudenthal (2002) states that the ratio can be classified as (i) internal or scalar (or ratio within a measurement space), if the magnitudes that constitute it shares the same measurement space; (ii) external or functional (or ratio between measurement spaces), when it is composed of magnitudes from different measurement spaces. Besides this classification, Freudenthal (2002) appeals to the phenomenological contextualisation of the concept and argues that a ratio can also be interpreted as a quotient, in which the internal ratio is a number (multiplicative comparison) and the external ratio is a magnitude different from the initial ones, designated, according to Lobato, Ellis, Charles, and Zbiek (2010), as a composite unit. When, for example, yellow and blue paint is mixed, we create a new colour (green) dependent on the quantities of the initial paints, which can be thought as a composite unit and which we can replicate whenever necessary. The amount of ink of each of the initial colours is then determined through an iteration (repetition) or partitioning (division) process, depending on whether the objective is to increase or decrease the blend that originated that green colour tone.

In the evolutionary and conceptual course of proportionality, we started by considering contextualised situations in which the student, more or less intuitively, performs operational procedures only in a measurement space (internal or scalar ratio). Then, the situations in context should allow him/her to interpret and perform procedures in two measurement spaces (external or functional ratio). At a later stage, he/she will find the link to the linear function in which interpretation and graphical representation are considered.

\section{FLEXIBILITY IN MULTIPLICATIVE COMPARISON}

Flexibility in solving tasks and specifically, multiplicative comparison problems is based on the idea that resolution strategies are constructed and not just used. Threlfall (2009), in the specific context of mental calculation, argues that mental calculation strategies are being constructed and not only used, i.e., they are not selected from a collection and then applied, but are of an emerging nature in the sense that we are choosing what to do with the numbers. "The calculation-strategy is not selected and applied, it is arrived to" (Threlfall, 2009, p. 548), i.e., the numbers that arise in a problem lead us to a personal calculation-strategy, built step by step. The strategy we construct depends, therefore, 
on our knowledge of numbers, their properties, and relationships (composition, decomposition, approximation, combination, substitution, ...) and their role at the operational level, i.e., greater knowledge allows us to master a greater number of options. Threlfall (2009) argues, thus, that flexibility in mental calculation arises from a "discovery", which may in part be unconscious, and which is influenced by a relationship of trust, ease, and viability experienced by each one in the context in question.

To the flexibility of mental calculation, considered as an appropriate way to act on a problem, Rathgeb-Schnierer and Green (2013) add the idea that only a dynamic combination of strategic means (composition and decomposition of numbers, use of analogies between different orders in the representation of numbers, ...), characteristics of problems, numerical regularities and their relationships allow it to be evidenced.

In this study, we reconcile these latter proposals with the ideas of Threlfall (2009) and consider that the flexibility of strategies (understood as calculation procedures) is a dynamic process that we progressively define. The construction of the strategy also develops in the relationship between the knowledge about concepts (understanding why do something) and procedures (understanding how to do something), the influence that each determines on the other and how much both are essential for mathematical understanding. According to Sfard (1991), in the construction of mathematical knowledge, the terms structural (concept) and operational (process) are inseparable, are "facets of the same thing" (p. 9) and it is this duality that must be explored and evidenced in the teaching and learning process.

\section{REPRESENTATIONS IN MULTIPLICATIVE COMPA- RISON}

The role of (external) representations has been discussed and valued in the mathematics teaching and learning process, in a very close connection with the understanding of concepts and procedures and the connections between them. According to the NCTM (2000), "representation is central to the study of mathematics" (p. 280) and, in the context of a classroom, the exploration of different representations in the resolution of a given task, its discussion and joint reflection on which is the most appropriate, are part of the process of mathematical communication to be developed throughout schooling. The relevance of representations arises, according to NCTM (2014), either in the actions of students (learning), for example, when they use various forms of representation to give meaning to a problematic situation or when they contextualise mathematical ideas in real-life situations; or in the actions of teachers (teaching), for 
example, when selecting tasks that allow students to decide on which representations to use or when requesting them to make drawings, schemes or other visual support to explain and justify their reasoning.

The connections between concepts, between modes of representation, and between concepts and modes of representation are positive factors for the learning process. Abrantes, Serrazina, and Oliveira (1999) refer specifically to the connections between the concept of ratio and the different modes of representation defended by Bruner (1966) - active, iconic, and symbolic - and which they call by concrete, figurative, and symbolic representations, respectively.

Concepts such as fraction, ratio, decimal, and percentage are key ideas to be worked on in situations that are significant to the students and that allow them to move from one representation to another, from concrete to figurative, and from figurative to the symbolic ones. (Abrantes et al., 1999)

Representations are, therefore, considered as tools to support the understanding of new concepts or procedures and problem solving. Vergnaud $(1983,1988)$ argues that the schematic representation of problems, as exemplified above, becomes important for its resolution and to highlight the role of multiplicative structures in the concept of multiplicative comparison. It makes no reference to the type of numbers involved and, as such, the quantities in each of the measurement spaces can be integers or non-integer numbers, represented in various forms.

At an early stage of learning, representation models should be, according to van Galen et al. (2008), very close to contextualised situations, but as schooling progresses, they should allow students to reason beyond a concrete situation. They suggest, therefore, the gradual replacement of "models of concrete situations by models for thinking" (p. 18), which they exemplify with the use and exploration of the double bar or the double number line with fractions, percentages, decimals, and proportions.

The use of several representations by students in the resolution of specific tasks appears, in this study, in a prominent position in relation to the discussion on flexibility in the conceptual evolution of multiplicative comparison. The ratio representation as a fraction is highlighted, as well as the use of tables and double number lines with integers and non-integer numbers. 


\section{MODEL OF FLEXIBILITY IN THE EVOLUTION OF THE UNDERSTANDING OF MULTIPLICATIVE COM- PARISON}

To analyse the flexibility in understanding the multiplicative comparison manifested by students in the resolution of tasks, we propose a model based on its conceptual evolution (Vergnaud, 1983, 1988) in which we identify three levels: multiplicative comparison in a measurement space; multiplicative comparison in two measurement spaces; functional comparison (linear function). In figure 2, these levels are indicated in the left column and each one is articulated (double-direction horizontal arrows) with the resolution strategies (second column, from left to right) and the representations (last column, from left to right) used by the students. These links between strategies and representations are driven by numerical aspects, numerical relationships, and properties of operations, chosen by students (double-sense horizontal arrows).

Flexibility is supported by the horizontal, double-direction relationships between the four columns and the vertical joints, from the bottom up, that symbolise the conceptual development of the multiplicative comparison. It is considered a dynamic process in the sense of adapting resolution strategies and the use of representations to the characteristics of tasks, in which numerical relationships and the properties of operations acquire a prominent role.

\section{Figure 2}

Flexibility and conceptual evolution of the multiplicative comparison.

\begin{tabular}{|c|c|c|c|}
\hline $\begin{array}{l}\text { Conctirita } \\
\text { Eveutrox }\end{array}$ & 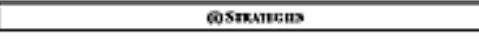 & 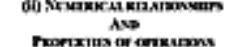 & 6en Rimicestunons \\
\hline 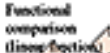 & 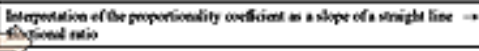 & 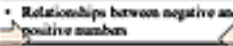 & Gowh \\
\hline \multirow{3}{*}{ 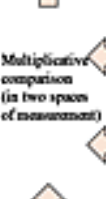 } & 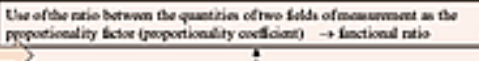 & \multirow{2}{*}{ 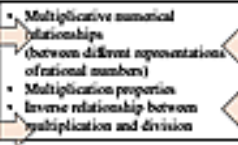 } & 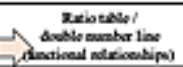 \\
\hline & 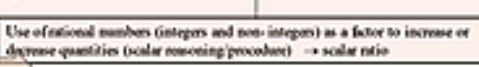 & & 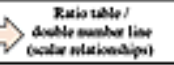 \\
\hline & 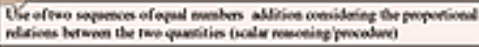 & 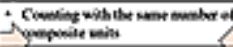 & 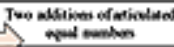 \\
\hline 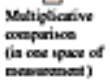 & & & \\
\hline
\end{tabular}




\section{METHODOLOGY}

With the objective of building a local theory on the flexible development of multiplicative comparison, this study follows a design-based research (DBR) methodology (Gravemeijer \& Cobb, 2013) with two research cycles.

The choice for DBR is justified because the objective of the study is based on the students' understanding of a particular mathematical topic when exploring, in the classroom, a sequence of tasks that constitute a hypothetical learning path defined from theory (Simon \& Tzur, 2004).

The first research cycle is carried out in a 6th-grade class with eighteen students (of whom seventeen are eleven and one thirteen years old), whose mathematics teacher, Sofia, has been teaching for 16 years. The second research cycle occurs in the following school year and is based on an adjustment of the learning trajectory used in the first. It is carried out in another 6th-grade class with twenty students (of whom fifteen are eleven, four are ten, and one is thirteen years old), and whose teacher, Vera, has 28 years of teaching experience. In the two research cycles, the first author of this article promotes work meetings with the teachers in which, after explaining the general lines of the project, she orchestrates an in-depth discussion of each task. We analyse the written documents in which we propose the statements of the tasks, their learning objectives, their framing in the mathematics official Portuguese curriculum, the indications of exploration of the tasks in the classroom, including the anticipation of resolutions and the probable errors of the students. At these working meetings, the medium-term planning previously established by the teachers is also adjusted and the scheduling of the teaching experience is agreed.

The first author of this article constructed an initial outline of the hypothetical learning trajectory from the theory (see next section), which was adjusted according to the contributions of the two teachers, essentially in the meetings mentioned before, and the preliminary analysis of the data related to the first research cycle.

The data collected ${ }^{1}$ includes the transcription of the video recordings of the classes of the two research cycles and all the students' written productions. The data analysis began with the detailed descriptions of each class that included the oral interventions during the presentations/discussions carried out

${ }^{1}$ The Informed Consent Form was signed by the guardians of the students participating in the study. The investigation followed the guidelines of the Letter of Ethics for Research in Education and Training of the Institute of Education of the University of Lisbon (http://www.ie.ulisboa.pt/download/carta-etica-eregulamento-da-comissao -de-etica), institution where the $\mathrm{PhD}$ thesis to which this article refers was approved (http://hdl.handle.net/10451/42867). 
there and the written productions recorded by the students. This body of data was successively reviewed to identify the aspects that make up the theoretical model (figure 2): (i) the resolution strategies used by students - they translate or not quantification; they are additive strategies associated with the repeated addition and associated with the decomposition of numbers; they are multiplicative strategies; (ii) the numbers used by students - integers, even or odd, multiples of ..., not integers represented as a fraction, decimal, mixed numeral or percentage; (iii) representations used by students - ratios represented as a fraction, double number lines, ratio tables; (iv) relationships between the elements considered in the previous paragraphs - prevalence or not of associations between the strategy, the type of numbers and the representations used, stability of the associations (they are, or they are not, always of the same type, they change, or they do not change, throughout the exploration of the tasks).

This article focuses on the resolution strategies used by students in the 1 st and 2 nd cycles of research in exploring Task 1 (Chocolate blends) and Task 4 (Making lemonades). The selection of these two tasks relates to the identification that the data relating to them cover all types of strategies identified in the research.

\section{THE TASKS AND THE MODEL}

The conceptual perspectives (concepts and procedures) of the multiplicative comparison allow us to idealise a learning path based on the design of a sequence of tasks, to be presented and explored in the classroom, in which the resolution proposals and the arguments the students present illustrate different levels of understanding in the construction of their mathematical knowledge.

The tasks chosen, in a total of five, and the respective learning objectives, are presented in the scheme in Annex 1, in the chronological order in which they were explored. The first one is "Chocolate blends" and the last one is "Which should I buy?!". From the curricular point of view, in both cycles of research, the theme Proportionality was still unknown to students and, as such, this hypothetical learning trajectory begins with an initial approach.

These tasks have their conceptual focus on the intermediate level referred to in figure 2, multiplicative comparison in two spaces of measurement, with evidence for the exploration of a scalar procedure/reasoning. Thus, during resolution strategies (corresponding, in the theoretical model, to the shaded part of figure 2), we highlight the modes of representation and the relevant numerical aspects in the responses of some of the students to illustrate the connections (horizontal, double-sense arrows) that allow us to highlight flexibility. 
The study includes tasks that, when considering, such as Ponte (2005), two of its fundamental dimensions, the degree of mathematical challenge and the degree of structure, have characteristics of problems, since they present a high degree of challenge, but with a closed structure.

The phenomenological contextualisation of these tasks emerges through mathematical connections with real life, some of the problems can illustrate everyday situations, and within mathematics itself, in the direct exploration of numerical relationships, between different types of numbers, and between different operations.

\section{FLEXIBILITY IN MULTIPLICATIVE COMPARISON - LANDMARKS}

Considering that the objective defined is to empirically support and illustrate a model that translates flexibility into the conceptual evolution of multiplicative comparison (figure 2), we base the analysis and discussion of data on the resolution strategies used by students.

\section{Strategies that do not translate into quantification}

The strategy associated with non-quantification emerges when students do not find necessary to quantify, that is, to keep record of the elements mentioned in the contexts of the tasks, and their concern is solely based on the identification of qualitative attributes.

In Task $1-$ Chocolate blends $^{2}$ (figure 3 ), in which one works in a discrete universe (unbreakable chocolate chips), no numerical data is expressed, and the initial question also does not make this situation explicit, which may have influenced the choice of some students for non-quantification.

2 Task design: Jean Marie Kraemer, 2015 (Numerical thinking and flexible calculation project: Critical aspects). 


\section{Figure 3}

Chocolate blends.

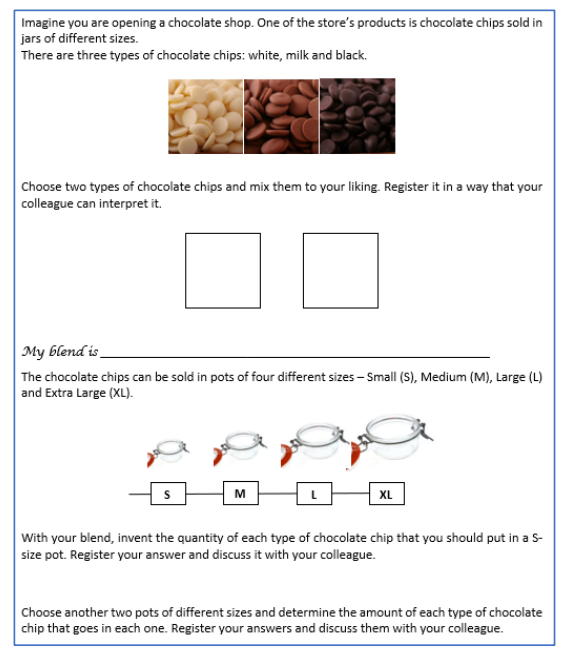

Filipe registers (figure 4) the choice of his blending of chocolate chips only in natural language but does not quantify any of the types (white and milk chocolate).

\section{Figure 4}

Filipe's register - non-quantified blend.
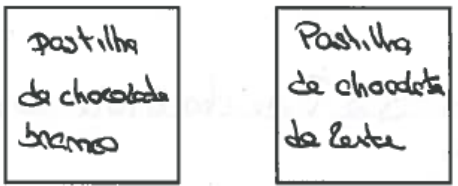

For Filipe, this information is sufficient to identify his blend, and he will only realise that it isn't effectively defined when he indicates the amount of each type of chocolate tablet after the teacher details that, to make "an equal blend", she needs more information and that the amount will influence the blend in the sense of being "or whiter, or blacker or darker".

\section{Additive strategies that translate quantification and multiplicative comparison}

A strategy of additive characteristics - adding equal numbers - but in which proportional relations between two quantities are maintained, implicitly presupposes that we associate it with multiplicative comparison and scalar reasoning. 
The strategy is linked to the counting in the use of the same number of composite units and in the symbolic representation of the reasoning developed through two repeated additions.

Mário and Helena choose 6 white chocolate and 6 milk chocolate chips for their mix. They consider it as "Data" (figure 5) and justify their choice, for the number of chocolate chips in the size $\mathrm{S}$ bottle, in the register they call "Calculation". They add twice the same amount (12) and therefore represent, in the form of a sum of equal numbers, the idea that the transformation carried out in the quantities of the two types of chocolate chips must be the same.

\section{Figure 5}

Mário's resolution - size S bottle.

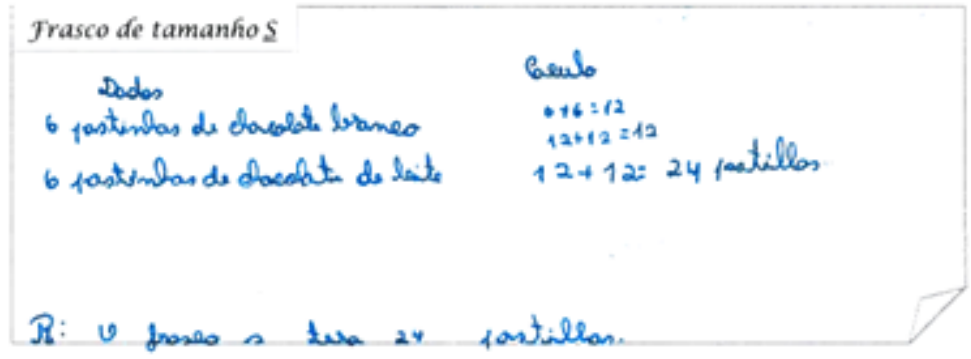

\section{Figure 6}

Bruno's resolution - size S bottle.

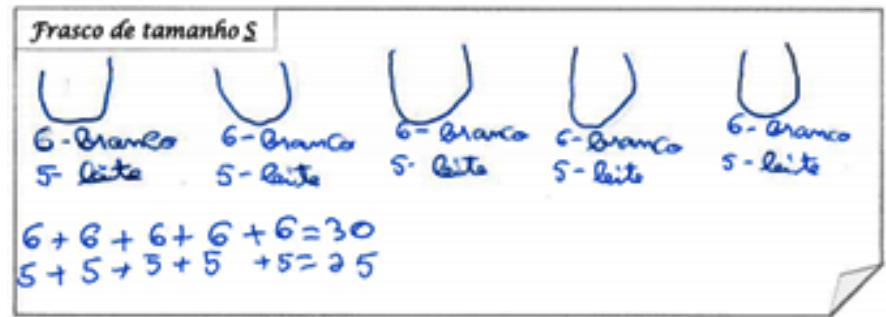

\section{Multiplicative comparison strategies and scalar ratio}

Another pair of students, Bruno and Vítor, present an additive relationship between the quantities of chocolate chips of the blend they chose (30 of white chocolate and 25 of milk chocolate) and those of the size $S$ bottle. They start from values that are both multiples of 5 and equitably distribute the two quantities by five bottles (size $S$ ). In figure 6 , we can observe how they register their idea, first, through iconic subtitled representations (very simple drawings, 
without any details, and unrealistic) and then in a symbolic representation (numerical translation of two additions of five equal numbers each).

A strategy with multiplicative characteristics emerges when a factor represented by a rational number (integer or non-integer) is applied to increase or decrease two quantities of different measurement spaces, maintaining proportional relations between them. The reasoning/procedure developed is of the scalar type, i.e., it originates the same concretisation/alteration within each of the spaces of measurement involved.

The symbolic mode of representation prevails, through ratios represented as a fraction, tables of ratios or double number lines in a scalar relationship, i.e., as mentioned, within each of the measurement spaces.

The integers that appear have, for the most part, one or two digits and are multiples of two or five; the non-integer numbers are represented as a fraction, a decimal, or a mixed numeral. The realisations/changes, induced by the tasks to explore the equality or not of ratios are often based on the use of number 2 as a factor and as a divisor, in translation of the elementary concept "the double of" and the calculation of "half of" through the division operation, respectively.

The multiplication and division operations are seen as inverse of each other when an unknown factor is identified with the quotient of the division between the product and the already known factor. The inverse relationship between these two operations also arises when, in an equality between ratios, the respective terms of the same measurement space appear multiplied or divided, for example, by two. This fact is an allusion that explains that: if within the same space we act in one direction, we use one of the operations; if we act in the opposite direction, the operation that corresponds to it is its inverse. However, if we keep the operation in both directions of actuation, then the numbers that arise are inverse of each other, i.e., dividing a number by another given number (other than zero) is equivalent to multiplying it by its inverse.

The work by Rita and Beatriz in Task 1 illustrates the use of this strategy of representation and numerical relationships mentioned before. The students choose their initial blend ( 32 white chocolate and 28 milk chocolate chips) and to indicate the quantities of chips of the bottles of sizes $\mathrm{S}, \mathrm{M}$, and L they use the whole 2, first to calculate half and then to duplicate each of the quantities (figure 7). In each question, they permanently choose to work with the last ratio found and always represent them as a fraction. From one ratio to another, they specify the procedure carried out in each of its terms through nonoriented and subtitled arcs. Thus, they divide both quantities of the initial blend 
by 2 and obtain the content of the size $S$ bottle, then multiply each of the quantities by 2 and obtain those of the size $M$ bottle and, finally, with the same procedure, obtain the quantities of chips of the size L bottle.

\section{Figure 7}

Rita and Beatriz's registers - bottles of various sizes.
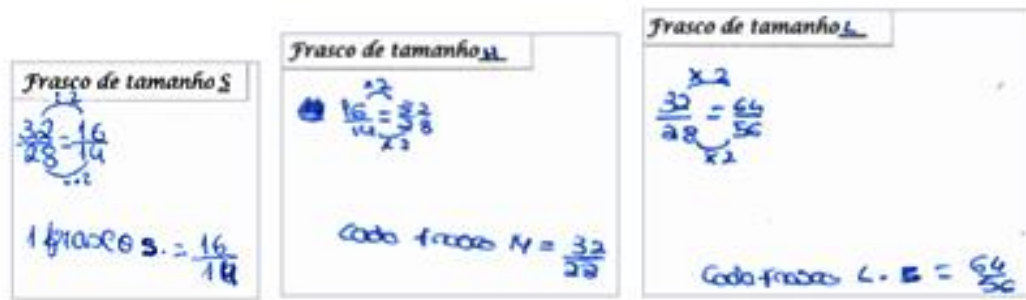

Manuel and Filipe, with an initial blend composed of 8 white chocolate and 6 milk chocolate chips, use a strategy, representations, and relationships identical to those used by Rita and Beatriz. However, the comparison factor 2 translates a relationship in only one direction (from left to right) to determine the quantity of chips of one bottle in relation to the other. A register of their response (Figure 8) shows a sequence of equalities between the various ratios, all represented as a fraction.

\section{Figure 8}

Manuel and Filipe's registers - bottles of sizes $M$ and $L$.
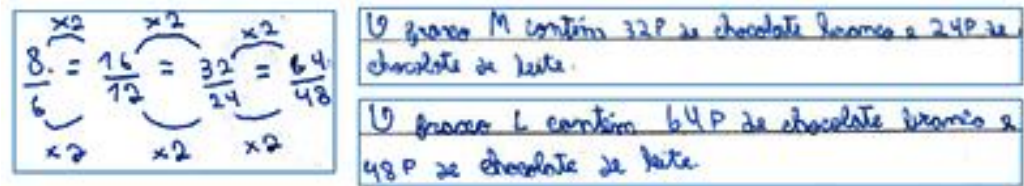

In Task 4 - Making lemonades ${ }^{3}$ (figure 9), a continuous universe (liquid) is explored, in which "making lemonades" imposes an action of blending two liquids of different types (water and lemon juice concentrate) using different units of measurement (litre and cup, respectively), to obtain a liquid with characteristics different from the initial ones.

${ }^{3}$ Adapted from Using Proportional Reasoning in Mathematics Assessment Project (2015). University of Nottingham \& UC Berkeley. 


\section{Figure 9}

Making lemonades (problem 1).

When Jožo and his friends get together to play, his mother makes lemonade, mixing lemon juice concentrate with water.

On Friday, Jošo's mother made lemonade and mixed 3 cups of lemon juice concentrate with 4 litres of water.

On Saturday, at JoJ̃o's birthday party, his mother made lemonade and mixed 4 cups of lemon juice concentrate with 5 litres of water.

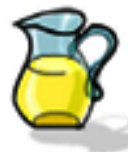

1. Some of João's friends said that Friday's lemonade had a different lemon flavour than Saturday's one. Do you agree with them? Explain your reasoning and show all the calculations you made.

The resolutions of this task by José and Renato also illustrate the multiplicative comparison strategy, choosing factors that allow them to multiplicatively relate quantities within the same measurement space and using the double number line.

José registers two double number lines in the resolution of problem 1, as shown in figure 10. The values appear, in each line, through the application of the respective natural multiples of the numbers that initially identify the quantities used in lemonades of Friday, 3 and 4, and Saturday, 4 and 5. The comparison between the elements of the two lines, respectively, allows him to understand that lemonades have different flavours when, at a given time, we get the same number of cups of lemon juice concentrate (12) and a different number of litres of water (16, on Friday, and 15, on Saturday).

\section{Figure 10}

José's double numeric lines.

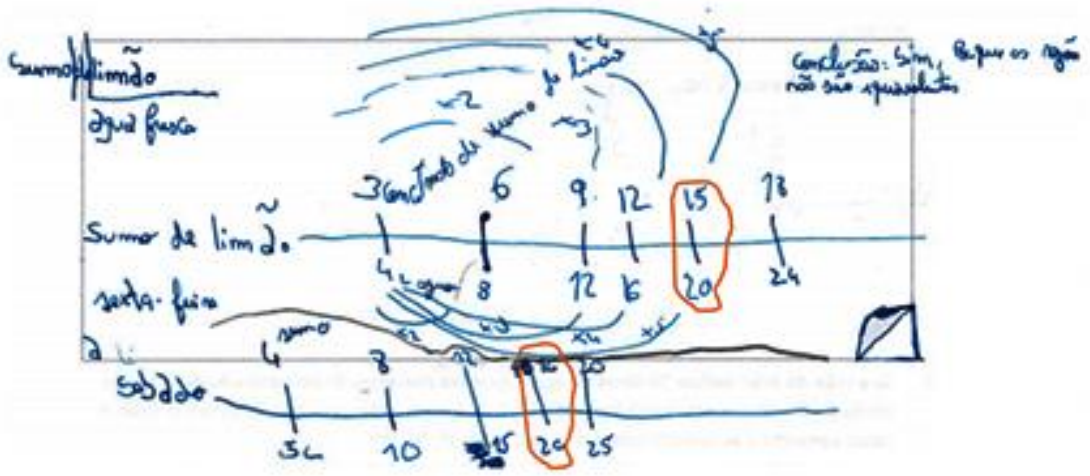

Renato registers (figure 11) the data for Friday and Saturday lemonades in a table of ratios and shows that the factor that allows him to multiplicatively 
compare the quantity of each of the ingredients of Saturday lemonade with the respective ingredients of Friday is not the same. It uses the division algorithm to determine this factor and registers it as a legend of the arrows that illustrate the relationship between one column and the other, i.e., it shows that the scalar relationship of the quantities of the two ingredients of Friday and Saturday lemonades is not maintained.

\section{Figure 11}

Renato's table and factors.

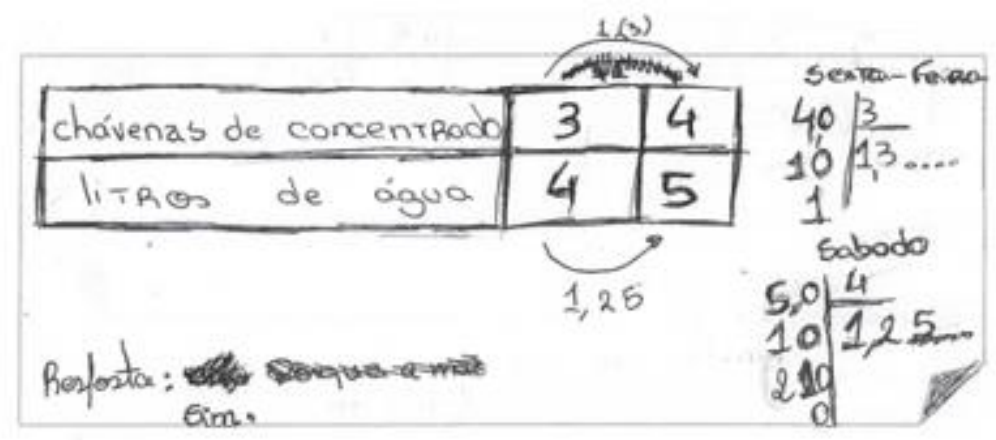

However, while José works with sequences of multiples (integer factors) and relates ratio and fraction through the concepts of equal ratios and equivalent fractions, Renato chooses to determine the factors that allow him, within a given measurement space, to compare the indicated quantities and does so through non-integer numbers. The factors sought are obtained by Renato through the division quotient, in a direct application of the inverse relationship between the multiplication and division operations.

Alexandre and Hugo, in solving problem 2 of this task (figure 12), also use the double number line, but do not maintain the ordering of the numbers in the number line (in ascending order, from left to right), but the order indicated in the wording, as if they considered it a table.

\section{Figure 12}

\section{Making lemonades (problem 2).}

2. Some days later, João's mother wanted to make lemonade with the same lemon flavour as the one she had made on Saturday, but she only had 1 cup of lemon juice concentrate. How much water should she use for that? Explain how you thought and show all the calculations you made. 
Alexandre complements the previous representation (figure 13) with a symbolic indication of the divisions made and whose non-integer quotient is indicated in the form of a decimal and a mixed numeral.

\section{Figure 13}

Alexandre's resolution.

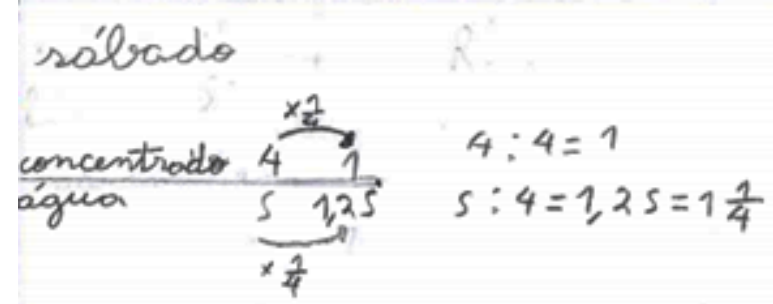

Alexandre explains his reasoning to the teacher (figure 14), who takes advantage of it for all students to remember the relationship between multiplication and division operations.

\section{Figure 14}

Relationship between divide by 4 and multiply by $\frac{1}{4}$.

Teacher - On Saturday there was...

Alexandre - Four of concentrate and five litres of water [points to the double number line] and they want only one of concentrate [points to 1 on the double number line]. So, we must see by how much we have to multiply or divide the four to get one.

Teacher - Here you are. Four to one, what did I do? Divided by... Student - Four.

Teacher - By four. Everyone thought of that. I will divide it by four, and I will get one. So, you practically did this and put it... so, I'm going to divide the five by four as well. But Alexandre... you can sit down, Alexandre. Thank you. Alexandre did something here that none had done.

Students - Times a quarter.

Teacher - We have already seen that dividing by four is the same as what?

Daniel - Times... do... times a quarter.

Teacher - Multiply by a quarter. Why?

Student - By the inverse.

Teacher - By the inverse.

Daniel - By the inverse.

Manuel presents (figure 15) a double number line with several points in which the numbers appear placed in an ascending order from left to right. $\mathrm{He}$ 
does not directly compare 4 and 1 , nor 5 and 1.25 , but indicates a calculation path based on successive divisions by 2 . Therefore, he determines the intermediate values, 2 and 2.5 and, similarly, indicates two more points to the right of the initial values ( 4 and 5), which appear by their multiplications by 2 and 3 . There are no written registers of calculations, which leads us to assume that they were made mentally, in a domain of basic knowledge of calculation with integers and non-integers numbers.

\section{Figure 15}

Manuel's double number line.

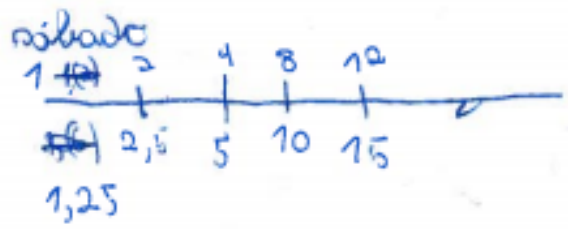

Rodrigo, without indicating any explanation of calculations, also uses (figure 16) a double number line, in which he marks three points that correspond to correct values of lemonades with the same flavour as on Saturday. He considers four double-oriented arcs subtitled in duplicate with the procedures of multiplying by 2, " $\times 2$ ", and dividing by 2, ": 2 ", showing knowledge about the inverse relationship between multiplication and division operations.

\section{Picture 16}

Rodrigo's resolution - double number line.

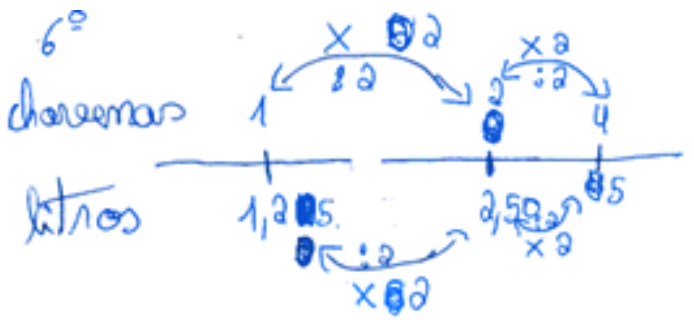

At this point, given the ratio unit in the previous problem, we assume that solving problem 3 (figure 17) makes it possible to establish a relationship with the previous answers, to facilitate non-algorithmic calculation procedures, and quickly and efficiently to arrive at the solution. 


\section{Figure 17}

Making lemonades (problem 3).

3. When they went on an excursion, João's mother made lemonade with the same flavour as the one she had made on Saturday and then, she mixed 9 cups of lemon juice concentrate with water. Can you tell how many litres of water she used? Explain your reasoning and show all the calculations you made.

Bruno represents (figure 18) a double number line with two points, two oriented arcs and subtitled with the procedure to be performed (" $\times 9$ ") and, without writing the answer to the problem, surrounds the point that relates 9 cups of lemon concentrate with 11.25 litres of water and that allows him to obtain a lemonade under the indicated conditions.

\section{Figure 18}

Bruno's strategy, based on ratio unit .

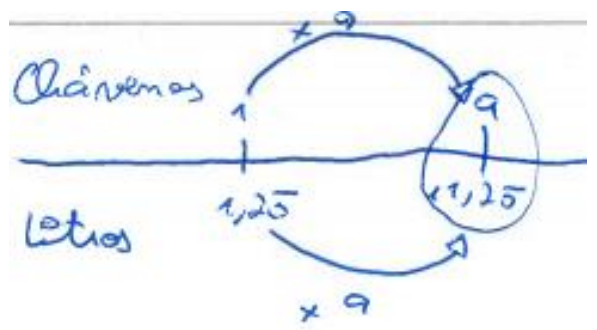

We do not know how he made the calculations, but Bruno adapts his strategy by not working with the initial data of the task, but with the values obtained in the previous problem and explains (figure 19) from where he started and why, when he is challenged by the teacher.

\section{Figure 19}

Bruno's justification for choosing the numbers.

Teacher - From where did you start?

Bruno [with the right indicator, points to the double number line 1 and then 1.25] - From... from the result he had given us in the previous exercise.

Teacher: -Well done! Why? Why did you take that one?

Bruno - Well, because I thought it was the easiest. I immediately thought mentally, one times nine equals nine. [With the right indicator, he circumvents the arc from 1 to 9.] And ours... here in the problem, it asked... uhum... nine cups... that she had to add nine cups. 
Not all students proceed like Bruno, some choose to work with the initial values of the task, with a ratio represented as a fraction, $\frac{4}{5}$. Andreia's resolution (figure 20) indicates that it first determines the scalar factor through the division algorithm applied at 9:4 and then multiplies the non-integer quotient obtained by 5 , again by applying the respective algorithm. In this operation, she registers, as a calculation aid, the intermediate values of the regroups.

\section{Figure 20}

Andreia's strategy, based on an initial ratio for the problem.
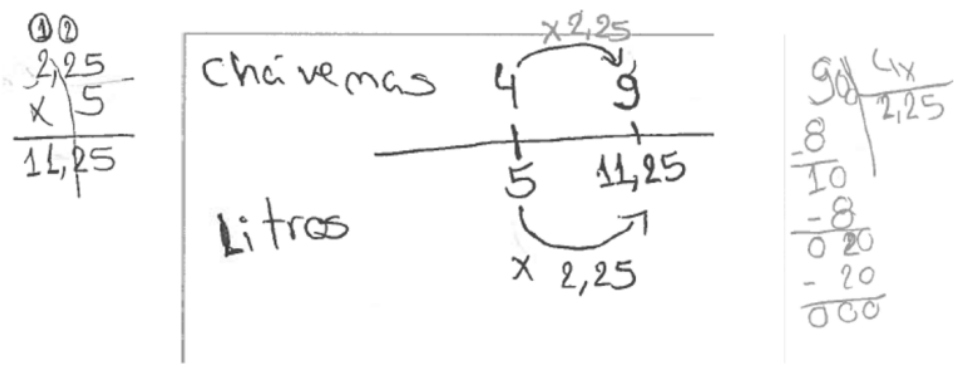

Mário, like Andreia, begins his resolution with ratio $\frac{4}{5}$, but uses only the representation as a fraction. He first calculates the non-integer quotient of 9 divided by 4 , through the division algorithm, and then $5 \times 2.25$, by applying the multiplication algorithm. He registers the two ratios (figure 21) side by side, and places subtitled arcs with the procedure to be performed $(\times 2.25)$ that link the first and second terms, respectively, from one ratio to another.

\section{Figure 21}

Mário's resolution, based on an initial ratio for the problem.

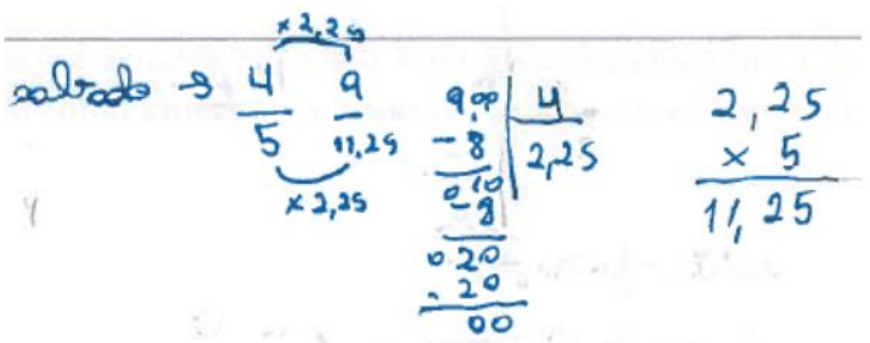

In the fourth problem of this task (figure 22), we intend to determine one of the terms of a ratio, when, simultaneously, the other is known and the 
multiplicative relationship to maintain is indicated, i.e., the taste of the lemonade made on a given day.

\section{Figure 22}

Making lemonades (problem 4).

4. Suppose João's mother uses 18 litres of water, how many cups of lemon juice concentrate should she mix so that the lemonade tastes the same as Friday's? Explain your reasoning and show all the calculations you made.

Bruno chooses to obtain two ratios equal to $\frac{3}{4}$ and represents his strategy through two double number lines with two points (figure 23). In the first, he presents two arcs oriented from right to left and captions them with the procedure of dividing by 2; in the second, he also places two arcs oriented from left to right and captions them with the procedure of multiplying by 9 .

\section{Figure 23}

Bruno's resolution - double number lines.

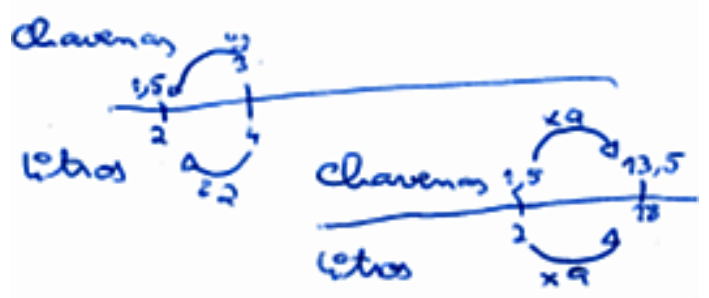

He does not explain how he made the calculations, but orally justifies his strategy and procedures (figure 24). The knowledge he has already acquired from multiples and dividers of a natural number, allow him to affirm that while 4 is not a factor of 18, 2 is a factor and, therefore, chooses it to build the sequence of procedures that, in his opinion, lead to more accessible intermediate calculations.

\section{Figure 24}

How Bruno justifies his calculation procedures.

Bruno - So, I took this number here [with the right indicator points to number 4 on the double number line where the points corresponding to the ratios $\frac{3}{4}$ and $\frac{1,5}{2}$ appear] and I divided by two because I thought right off the bat that two times nine was eighteen [points quickly to the lower number line, where the points corresponding to the ratios $\frac{1,5}{2}$ and $\frac{13,5}{18}$ appear] and then 
I found an equivalence to make my calculations easier. And then the result was... I divided the three by two, the result was one comma five, and the four divided by two, which gave two as a result. Then (...) it multiplied by nine.

Bruno's, Andreia's and Mário's procedures are similar, but Bruno shows appropriate management of the calculations to be made when, on the one hand, he uses the information he has at his disposal and that he had obtained before and, on the other hand, he applies properties of the numbers to obtain those that are most accessible to him for mental calculation.

\section{Multiplicative comparison strategies and functional ratio}

Another multiplicative comparison strategy becomes dominant when, before a data set, the factor, whether integer or not, is determined, which allows relating an amount of one measurement space to an amount of the other measurement space through a single constant. This situation, based on the relationship between two spaces of measurement, evidences a functional procedure/reasoning and makes it possible to identify the proportionality coefficient. The data analysis registered in a collection of ratios, represented as a fraction, allows for the identification of a numerical regularity that relates multiplicatively, at each moment, one quantity to another, from one measurement space to another (functional ratio).

In view of some of the blends of chocolate chips suggested in Task 1 and registered in the table, students identify as being the same blends that are represented by ratios $\frac{10}{5}$ (10 white chocolate and 5 milk chocolate chips), $\frac{100}{50}$ (100 white chocolate and 50 milk chocolate chips) and $\frac{20}{10}$ (20 white chocolate and 10 milk chocolate chips). One of them justifies these options because as the student states "the division will always be 2 " $(10: 5=2 ; 100: 50=2$; $20: 10=2$ ).

Thus, to multiplicatively compare the number of white chocolate chips in relation to the number of milk chocolate chips is to consider that the factor that allows representing the number of white chocolate chips as a function of the number of milk chocolate chips is constant and, in this case, equal to two: $10=2 \times 5 ; 100=2 \times 50 ; 20=2 \times 10$.

Later, the exploration of this situation allows using properties of the non-integer numbers and properties of the multiplication operation in which, for example, in the first of the ratios, $\frac{10}{5}$, we can, as mentioned, compare the 
quantity of white chocolate chips, 10 , in relation to the quantity of milk chocolate chips, 5 , and register that $10=2 \times 5$. However, since $\frac{10}{5}=2$, also $10=\frac{10}{5} \times$ 5 , and $\frac{10}{5}$ is, therefore, a functional ratio.

\section{CONCLUSIONS AND DISCUSSION}

The data analysis allows us to illustrate and adjust the model that characterises flexibility at the level of the conceptual evolution of the multiplicative comparison, basing its specification, translated in figure 25 .

\section{Figure 25}

Adjusted model of flexibility in the evolution of the multiplicative comparison.

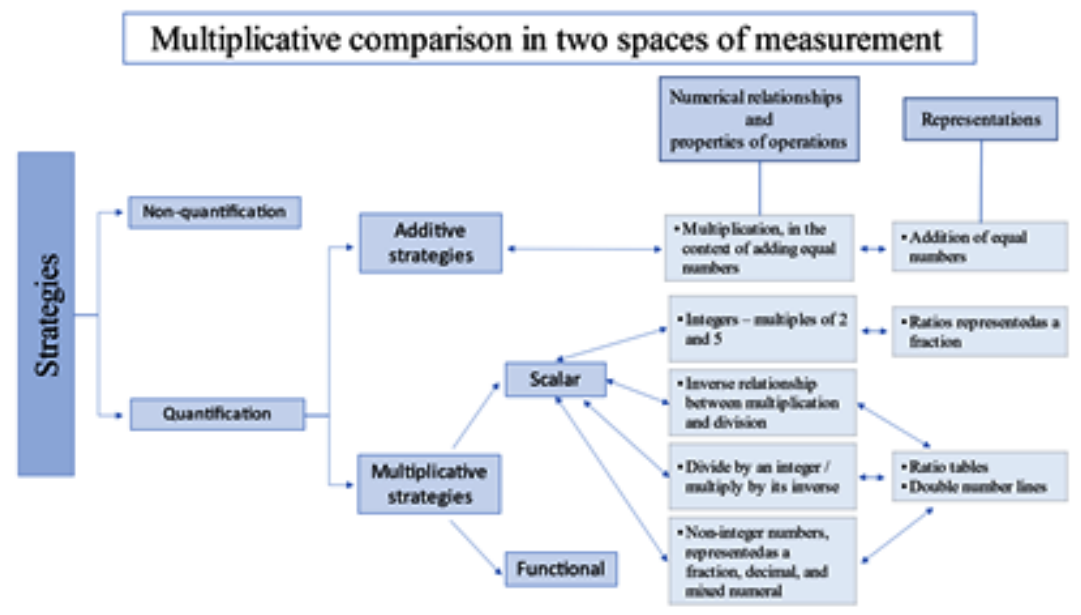

Regarding the conceptual evolution of the multiplicative comparison, we identified a level initially used by some students, in which, although working in two spaces of measurement, its resolution strategy is based on non-quantification, limited to a qualitative description of the elements involved (Filipe's case, in Task 1).

Always remaining in the multiplicative comparison in two spaces of measurement, the resolution strategy of these students evolves into quantified situations in which we highlight: on the one hand, additive strategies, in which the operation that appears is the repeated addition that is symbolically translated (Mário's and Bruno's cases, in Task 1) and in which the numbers involved 
are integers, multiples of 2 and 5, considered accessible from the point of view of calculation; on the other hand, multiplicative strategies, in which the ratio is represented as a fraction, tables of ratios, or double number lines and whose interpretation leads to the procedure adopted.

When the ratio is represented as a fraction, the numbers involved are integers that arise by determining the multiples of 2 (Manuel's and Filipe's cases, in Task 1). In the ratio represented in double number lines or tables, the numbers are integers or non-integers, determined by the search for common factors in each of the measurement spaces, through the division operation (Alexandre's and Andreia's cases, in Task 1, and Renato's, in Task 4). Both cases allow underscoring the inverse relationship between multiplication and division operations. Rodrigo registers (figure 16) this correspondence when he places arcs oriented in both directions between the corresponding values of points of the double number line. Another connection also becomes visible when Alexandre, by relating quantities within the same measurement space, registers a non-integer factor, $\frac{1}{4}$, determined after the division by 4 . Alexandre understands that the procedure of dividing by 4 is equivalent to multiplying by its inverse (figure 13).

Although the algorithmic application of operations (multiplication and division) has great adherence to the calculation procedures carried out by these students, Bruno manifests knowledge of basic numerical relationships, and $a$ specific noticing at the numbers (figures 18, 19, 23, and 24) allows him to build and adapt his calculation strategies, for example, by using results from previous questions.

The students are comfortable in the various representations of a noninteger number (as a fraction, a decimal, or a mixed numeral) because, in addition to interpreting them, they alternate them, and choose the one that best suits their calculations.

\section{Implications at curriculum level}

The model we propose (figure 25), by specifying and actualising the theoretical model initially presented (figure 2), contributes to deepening the discussion about the teaching and learning of multiplicative comparison. It highlights aspects that the NCTM (2014) emphasises as fundamental for the development of mathematical proficiency - conceptual understanding, strategic competency, and adaptive reasoning - which here translates into the articulation between strategies, numerical relationships/properties of operations and representations, allowing to specify characteristics of each one of them. 
It emphasises, therefore, that it is important that the teacher, when organizing the teachers' activities, considers milestones articulated with, conceptual understanding that reflect: (i) the need to quantify the comparison; (ii) to use the multiplication operation; (iii) to use the scalar factor, and (iv) to use the functional factor. As for strategic competence, the teacher should encourage the exploration and use of numerical relationships (multiples and dividers, inverse numbers,...), properties of operations (commutative property of multiplication and distributive property of multiplication) and representations that may be associated with the concepts in question (table of ratios, double number line, and ratio as a fraction). Finally, at the level of adaptive reasoning, the teacher must stimulate the diversity of ways of thinking that support the resolution of problems involving multiplicative comparison.

This model also highlights the need to thoroughly study the work of multiplicative relations with rational numbers, to include the use of various integer operators, different from just 2 and 5. It also emphasises the students' tendency to remain in the relationships that are established within each measurement space and the difficulty in naturally progressing to the functional relationship (between measurement spaces).

Underlying this model, we underscore Thompson and Saldanha's (2003) curricular recommendation to focus on the understanding that a rational number represented as a fraction, $\frac{a}{b}$, corresponds to the number by which one must multiply $b$ to obtain $a\left(a=\frac{a}{b} \times b\right)$, a fundamental knowledge for the conceptual understanding of a functional operator.

Finally, the study foregrounds what Lamon (2007) and van Galen et al. (2008) refer to in relation to proportionality, considered as a hinge concept between different levels of education, and also places the understanding of the concepts of ratio and proportion at a more complex level of understanding, which requires a systematic exploration with different contexts and articulated with the multiplication of rational numbers (Freudenthal, 2002).

\section{AUTHORSHIP CONTRIBUTION STATEMENT}

G. C. and J. B. conceptualised the article, deciding on the theoretical incidence and methodology. G. C. was responsible for collecting the data and organising the teaching experience. Both authors also discussed the empirical evidence to be included in the data analysis, the conclusions to be drawn, and the final discussion. 


\section{DATA AVAILABILITY}

The data supporting the results of this study are openly available at Repositório da Universidade de Lisboa through http://hdl.handle.net/10451/42867.

\section{REFERENCES}

Abrantes, P., Serrazina, L., \& Oliveira, I. (1999). A matemática na educação Básica. Ministério da Educação, Departamento de Educação Básica.

Bruner, J. (1966). Toward a theory of instruction. Havard University Press.

Cramer, K., Post, T., \& Currier, S. (1993). Learning and teaching ratio and proportion: research implications. In D. T. Owens (Ed.), Research ideas for the classroom - Middle grades mathematics (pp. 159-178). Macmillan.

Freudenthal, H. (2002). Didactical phenomenology of mathematical structures. Kluwer.

Gravemeijer, K., \& Cobb, P. (2013). Design research from the learning design perspective. In T. Plomp, \& N. Nieveen (Eds.), Educational design research (pp. 72-113). Netherlands Institute for Curriculum Development (SLO).

Lamon, S. (2007). Rational numbers and proportional reasoning - Toward a theoretical framework for research. In F. Lester (Ed.), Second handbook of research on mathematics teaching and learning (pp. 629667). National Council of Teachers of Mathematics.

Langrall, C., \& Swafford, J. (2000). Three balloons for two dollars - Developing proportional reasoning. Mathematics Teaching in the Middle School, 6, 254-261.

Lobato, J., Ellis, A., Charles, R., \& Zbiek, R. (2010). Developing essential understanding of ratios, proportions, and proportional reasoning for teaching mathematics in grades 6-8. National Council of Teachers of Mathematics

National Council of Teachers of Mathematics. (2000). Principles and standards for school mathematics. National Council of Teachers of Mathematics. 
National Council of Teachers of Mathematics. (2014). Principles to actions: Ensuring mathematical success for all. Versão Portuguesa. Associação de Professores de Matemática.

National Research Council. (2001). Adding it up: Helping children learn mathematics. J. Kilpatrick, J. Swafford, \& B. Findell (Eds.). Mathematics Learning Study Committee, Center for Education, Division of Behavioral and Social Sciences and Education. National Academy Press.

Pittalis, M., Christou, C., \& Papageorgiou, E. (2003). Students' ability in solving proportional problems. In Proceedings of the 3rd European Research Conference in Mathematics Education. Bellaria: Italy, 3, http://www.dm.unipi.it/ didattica/CERME3/proceedings/Groups/TG3/TG3 list.

Ponte, J. (2005). Gestão curricular em Matemática. In GTI (Ed.), O professor e o desenvolvimento curricular (pp. 11-34). Associação de Professores de Matemática.

Rathgeb-Schnierer, E., \& Green, M. (2013). Flexibility in mental calculation in elementary students from different math classes. In B. Ubuz, Ç. Haser, \& M. A. Mariotti (Eds.), Proceedings of the Eighth Congress of the European Society for Research in Mathematics Education, CERME 8 - Eighth Congress of the European Society for Research in Mathematics Education (pp. 353-362). Middle East Technical University.

Sfard, A. (1991). On the dual nature of mathematical conceptions: reflections on processes and objects as different sides of the same coin. Educational Studies in Mathematics, 22, 1-36.

Simon, M., \& Tzur, R. (2004). Explicating the role of mathematical tasks in conceptual learning: an elaboration of the hypothetical learning trajectory. Mathematical Thinking and Learning, 6(2), 91-104.

Thompson, P. (1994). The development of the concept of speed and its relationship to concepts of rate. In G. Harel, \& J. Confrey (Eds.), The development of multiplicative reasoning in the learning of mathematics (pp. 181-234). Suny.

Thompson, P., \& Saldanha, L. (2003). Fractions and multiplicative reasoning. In J. Kilpatrick, W. G. Martin, \& D. Schifter (Eds.), A research companion to the principles and standards for school mathematics (pp. 95-114). National Council of Teachers of Mathematics. 
Threlfall, J. (2009). Strategies and flexibility in mental calculation. ZDM Mathematics Education, 41(5), 541-555.

van Galen, F., Feijs, E., Figueiredo, N., Gravemeijer, K., Herpen, E., \& Keijer, R. (2008). Fractions, Percentages, Decimals and Proportions. Sense.

Vergnaud, G. (1983). Multiplicative structures. In R. Lesh, \& M. Landau (Eds.), Acquisiton of mathematics concepts and processes (pp. 127174). Academic Press.

Vergnaud, G. (1988). Multiplicative structures. In J. Hiebert, \& M. Behr (Eds.) Number concepts and operations in the middle grades (pp. 141-161). Lawrence Erlbaum \& NCTM. 


\section{ANNEX 1}

Sequence of tasks and respective learning objectives
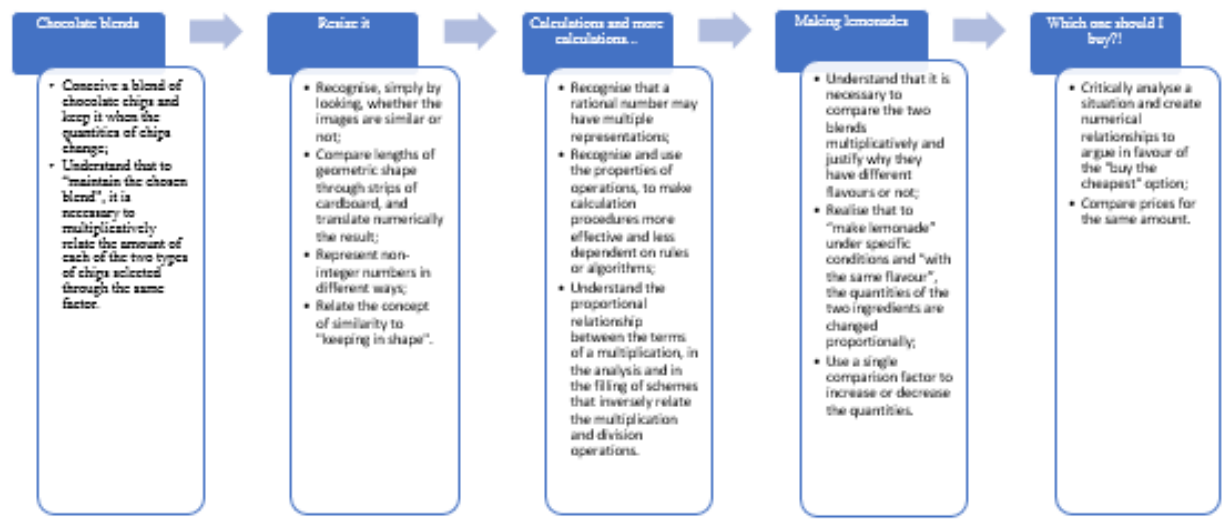